\title{
Effects of the ovary and conceptus on uterine blood flow in the pig
}

\author{
S. P. Ford and S. L. Stice \\ Department of Animal Science, Iowa State University, Ames, Iowa 50011. U.S.A.
}

\begin{abstract}
Summary. Changes in uterine blood flow throughout pregnancy appear to be due to steroid-induced alterations in uterine arterial tone and contractility. Arterial contractility is a transient reduction in luminal diameter in response to nerve stimulation or to an alpha-1 adrenergic agonist, leading to short-term reduction in uterine blood flow. Tone is the pressure exerted by an arterial segment against an intraluminal flow (distensibility) and is considered to set the baseline rate of flow. These phenomena appear to be regulated individually, with tone changes predominating during pregnancy. In pregnancy, tone is markedly depressed as oestrogen concentrations rise, and the vessel is distended and flaccid. Arterial tone is a function of the amount of calcium available to the contractile proteins of the arterial smooth muscle, which is derived from extracellular sources. Calcium availability is regulated by the opening and closing of calcium channels in the surface membrane in response to changes in the membrane potential. The loss of uterine arterial tone associated with oestrogen results from a markedly depressed uptake of calcium by the vessels. A significant negative correlation $(P<0.001 ; r=-0.93)$ is observed between uterine arterial uptake of calcium and the concentrations of oestrogens in systemic blood of pigs throughout gestation. Several lines of evidence suggest that the blockade of potential-sensitive calcium channels associated with uterine hyperaemia is produced by catechol oestrogens, short-lived metabolites of oestrogens that are found in the circulation when oestrogen levels are high. Synthesis of catechol oestrogens from the parent oestrogens has been shown to occur in the placenta, endometrium and uterine arteries of pigs. In addition, perfusion of uterine arteries from nonpregnant pigs with catechol oestrogens, but not free oestrogens, in vitro significantly reduces both the tone and the uptake of calcium by the vessels. Contractility of the arteries to nerve stimulation or phenylephrine, however, is not affected. These data suggest that the pig conceptus, through production of catechol oestrogens, locally increases arterial distensibility, resulting in increased baseline flow to each fetal-placental unit. The contractility (reactivity) of the uterine arterial vasculature to adrenergic agonists or other vasoactive agents, however, is not affected. In this way, the conceptus can maintain the locally elevated flows necessary for its survival while the maternal system can continue to respond to life-threatening stimuli by transiently rerouting blood flow away from the uterus and towards other vascular beds more necessary for maternal survival.
\end{abstract}

\section{Introduction}

Previous research from our laboratory (Ford \& Christenson, 1979) has provided clear evidence that one of the first interactions between the pig conceptus and the uterus is a local effect of the conceptus on increasing uterine blood flow. Some investigators argue that control of the uteroplacental vasculature is designed to protect the life of the fetus, whereas others stress the importance of 
maternal survival. It seems appropriate to the authors, however, that the utero-placental vasculature should be dilated under optimal physiological conditions, yet be ready to respond to vasoconstrictive stimuli that occur whenever there is a threat to the life of the mother. Evidence for this hypothesis was presented by Greiss \& Gobble (1967), who succeeded in almost completely obliterating uterine blood flow of late-pregnant ewes when the uterine periarterial sympathetic nerves were subjected to electrical stimulation or noradrenaline. We have observed similar transient reductions in uterine blood flow in response to acute stress in late-pregnant sows (S. P. Ford \& L. P. Reynolds, unpublished observations). In both the foregoing studies, the induced reductions in uterine blood flow were characterized by a rapid onset, brief duration and rapid return to original flows. In the discussion to follow, we attempt to summarize current thinking about the control of uterine blood flow during the oestrous cycle and throughout pregnancy, with emphasis on the pig.

\section{Blood flow, arterial contractility and arterial tone}

In nonpregnant pigs, the lowest flows occur during the luteal phase of the oestrous cycle when circulating progesterone concentration is high and oestrogen concentration is low (Ford, 1982). With the decline in progesterone at Day 16 and the preovulatory rise in oestrogens (oestrone + oestradiol-17ß), uterine blood flow increases 3- to 4-fold. High uterine blood flows are maintained for 2-3 days, then decline as new corpora lutea begin the production of progesterone. In pregnancy, the decline in uterine blood flow for the first 11 days is similar to that observed during the oestrous cycle. This decline is followed by a sharp peak of blood flow on Days 12 and 13 after mating and then by a progressive, dramatic increase beginning on Day 19, the first day of fetal attachment (Knight, Bazer, Thatcher, Franke \& Wallace, 1977), which continues until Day 50 (Hard \& Anderson, 1982), and then blood flow remains relatively constant until term (Ford, Reynolds \& Ferrell, 1984b). Flows of approximately $2500 \mathrm{ml} / \mathrm{min}$ at term are maintained into labour and decline in a step-wise fashion with the delivery of each fetus and placenta. These changes in uterine blood flow appear to be due to steroid-induced alterations in uterine arterial tone and contractility. Contractility is defined by the authors as a transient reduction in luminal diameter in response to nerve stimulation or to an alpha-1 adrenergic agonist, leading to short-term reductions in uterine blood flow. Tone is the pressure exerted by an arterial segment against an intraluminal flow (distensibility). Tone of an artery is considered to set the baseline rate of flow. These phenomena appear to be regulated individually, with contractility changes predominating during the oestrous cycle, while tone changes are dominant during pregnancy.

\section{Arterial contractility and regulation of calcium by receptor-operated channels}

Increased contractility produces the shortening of a muscle fibre and, in a blood vessel, causes a narrowing of the lumen and an increase in perfusion pressure. Contractility is a function of the amount of calcium presented to the contractile proteins of the vascular smooth muscle. Calcium for contraction is regulated by the binding of agonists such as noradrenaline to their receptors on the cell surface (Boiton, 1979). Activation regulated by the binding of agonists to these receptors initiates a contraction via release of calcium from intracellular stores (e.g. sarcoplasmic reticulum, mitochondria). This contraction is enhanced by concomitant opening of receptor-operated calcium channels in the cell surface and the entry of extracellular calcium.

Arterial contractility, therefore, is a function of the density and affinity of the adrenergic receptors and the availability of agonists for interaction with those receptors. Experimentally, the presence and activity of receptor-operated channels can be identified by monitoring contractility of and/or ${ }^{45} \mathrm{Ca}$ influx into vessels in response to agonists delivered in perfusates or to nerve stimulation (Bhalla, Webb, Singh, Ashley \& Brock, 1978). Ablation of these contractions by the general receptor-operated channel blocker, amrinone (Meisheri, Hwang \& Van Breemen, 1981), and by the 
selective receptor antagonists, are used to confirm a receptor-operated channel mechanism and to identify the agonist/receptor which is involved.

\section{Uterine arterial contractility and regulation of receptor-operated channels by progesterone}

As previously stated, contractility changes are most apparent during the oestrous cycle. The contractility changes reflect differences in circulating, or more specifically, local concentrations of progesterone. Uterine arterial contractility is highly correlated with the levels of progesterone in systemic blood (Ford, Weber \& Stormshak, 1977; Ford, Reynolds, Farley, Bhatnagar \& Van Orden, 1984a). The dependence upon local concentrations of progesterone is apparent from the observation that, in unilaterally ovulating ewes and cows, there is a significantly greater contractility of the uterine artery on the side ipsilateral to the ovary containing corpora lutea than on the contralateral side (Ford et al., 1976).

The ability of progesterone to alter uterine arterial contractility has also been shown experimentally. Gilts ovariectomized during the luteal phase of an oestrous cycle show a decline in uterine arterial contractility and alpha-1 adrenergic receptor density levels characteristic of those observed at oestrus (Van Orden, Farley, Reynolds \& Ford, 1982). Luteal-type contractility can be restored in long-term ovariectomized animals by administration of progesterone, but not oestrogen (Ford $e t$ al., 1977) whereas arterial tone, was not modified by progesterone treatment (Ford et al., 1977). The significant correlation of uterine artery contractility with circulating progesterone levels observed during the oestrous cycle is lost in pregnancy. This is understandable if one considers that contractility is a function of alpha- 1 adrenergic receptor activity and that the alpha-1 activity is determined by the density of the receptors and the availability of the agonist, noradrenaline. In nonpregnant and eariy pregnant pigs, progesterone is highly correlated with the density of alpha-1 adrenergic receptors (Ford et al., 1983; 1984a) and oestrogen is negatively correlated with the noradrenaline available for activation of that receptor.

In the luteal phase, therefore, when progesterone is high and oestrogen is low, the high arterial alpha-1 receptor density and high arterial noradrenaline content lead to marked contractility increase. At oestrus, the steroid hormones are reversed, the alpha-1 receptor density and noradrenaline content are suppressed, and the contractility is low. In pregnancy, both hormones are elevated; hence, alpha-1 receptors are abundant, but they lack agonist to cause contractility. Since there is no known interaction of progesterone with vascular alpha-1 adrenergic receptors, changes in receptor density may reflect synthesis rather than down-regulation of alpha-1 receptors.

If progesterone were to guide synthesis of alpha-1 receptors in the uterine artery, one should be able to show binding of progesterone by the uterine artery and identify the route by which the steroid reaches the artery. The ovary is the obvious source in nonpregnant animals, and it remains the source in the pregnant pig, since the placenta of the pig cannot synthesize progesterone (du Mesnil du Buisson \& Dauzier, 1957). Ovarian progesterone may reach the uterine artery via perivascular lymphatics as ovarian lymph, which runs in close proximity to the uterine arterial vasculature in the ewe and sow, contains high concentrations of progesterone, which exceed those found in systemic blood (Morris \& Sass, 1966; S. P. Ford, unpublished observations). In addition, binding of progesterone by the uterine artery is significant and is higher in the uterine artery ipsilateral to the ovary bearing the corpus luteum (Pope, Maurer \& Stormshak, 1982).

While the alpha-1 adrenergic receptor density is controlled by progesterone, uterine arterial noradrenaline appears to be regulated by oestrogen and there is therefore a significant fall in uterine arterial noradrenaline at oestrus in the pig (Ford et al., 1983). In the rat, uterine noradrenaline falls in response to oestrogen from the ovary or exogenous sources (McKercher, Van Orden, Bhatnagar \& Burke, 1973; Van Orden, Goodale, Baker, Farley \& Bhatnagar, 1980). Histochemical techniques have identified the periarterial neuronal noradrenaline stores as the uterine pool of noradrenaline that is responding to oestrogen in the rat (McKercher et al., 1973). Oestrogen may regulate neuronal noradrenaline in a variety of ways. Pedroza-Garcia, 
Garcia-Bienere, Inglesi, Szerezewski \& Rosner (1975) have reported that oestrogen reduces the uptake of noradrenaline by the human uterus. Furthermore, Lloyd \& Weisz (1978) have shown that the hydroxylated oestrogens can inhibit tyrosine hydroxylase, which is the rate-limited enzyme in noradrenaline biosynthesis. Finally, oestrogen also prompts accelerated degradation of noradrenaline by increasing catechol-o-methyl-transferase (Giles \& Miller, 1967).

\section{Arterial tone and regulation by potential-sensitive calcium channels}

Muscle tone is defined as the resistance of a muscle to 'stretch' (Ganong, 1977). In the context of uterine blood flow, it is the resistance to distension of the vessel that sets the baseline rate of flow and tone is a function of the amount of calcium available to the contractile proteins of the arterial smooth muscle (Bolton, 1979). Calcium for tonic contraction is derived from extracellular sources and calcium availability is regulated by the opening and closing of calcium channels in the surface membrane in response to changes in the membrane potential. Classically, changes in tone occur slowly, over a period of many minutes. It is possible to assess the permeability of those 'potentialsensitive' channels in vitro by comparing the perfusion pressure of the vessel upon excision (Ford et al., 1976) with that during perfusion of pharmacological agents that induce maximum and minimum tone. Commonly, maximum tone is elicited by exposure of the vessel to depolarizing concentrations of $\mathrm{KCl}$ or to perfusates high in calcium; minimum tone occurs in the presence of blockers of 'potential-sensitive' channels such as D-600 (methoxyverapamil; Janis \& Scriabine, 1983).

Uterine arterial tone and conceptus-mediated reduction in calcium uptake through potential-sensitive channels

In the oestrous cycle, uterine arterial tone is lowest (distensibility highest) at oestrus when circulating oestrogen values are high. In pregnancy, tone is markedly depressed as oestrogen concentrations rise, and the vessel is distended and flaccid (Ford, 1982). Insight as to the cause of the reduced tone in pregnancy comes from our in-vitro perfusion studies. Uterine arteries from Day-13 pregnant animals are flaccid and exhibit a reduced increase in perfusion pressure when exposed to depolarizing concentrations of $\mathrm{KCl}$ as compared to vessels from pigs on Day 13 of the oestrous cycle (Stice, Van Orden \& Ford, 1985). Contractility of these Day-13-pregnant uterine arteries to the alpha-1 adrenergic agonist phenylephrine, however, remained high and was equal to that of vessels from Day-13 nonpregnant pigs. Recent results from our laboratory (S. P. Ford \& S. L. Stice, unpublished results) have demonstrated that the contractility of uterine arteries to phenylephrine remains constant from Day 20 to Day 110 of gestation. Response of uterine arteries from pregnant pigs to $\mathrm{KCl}$, however, decreased from Days 13 to 20 and again from Days 20 to 50, and then remained relatively constant through Day 110 . As previously stated, uterine blood flow follows an inverse pattern throughout pregnancy, increasing to Day 50 then remaining constant through Day 110. These data suggest that the presence of the conceptus is associated with a progressive blockade of 'potential-sensitive' calcium channels, reducing the uptake in extracellular calcium and resulting in increased uterine blood flow.

\section{Evidence for two distinct populations of calcium channels in uterine artery smooth muscle}

As previously stated, we define tone as the resistance to distension established by an arterial segment to a constant intra-luminal flow for $30 \mathrm{~min}$ and recorded as a pressure in $\mathrm{mm} \mathrm{Hg} \mathrm{(Fig.} \mathrm{1).}$ Once the vessel has established this baseline perfusion pressure (baseline tone), it will remain constant and return to this pressure even after exhibiting transient increases in contractility in response to nerve stimulation, exposure to the $\alpha_{1}$-agonist phenylephrine or to a depolarizing dose of $\mathrm{KCl}$. Infusion of amrinone (Fig. 1a), a purported blocker of receptor-operated calcium channels 
(Meisheri et al., 1981), eliminates the contractile response of the vessel to alpha- 1 agonist and nerve stimulation, but fails to alter the response of the vessel to $\mathrm{KCl}$ or its baseline perfusion pressure. However, if the vessel is constantly perfused with D-600 (Fig. 1b), a selective blocker of potential sensitive calcium channels (Janis \& Scriabine, 1983), the baseline perfusion pressure is significantly reduced over a 15 - to 20 -min period: After infusion of D-600 for $30 \mathrm{~min}$, a new baseline perfusion pressure is established, which is significantly lower than the original, but the contractile response of the vessel is maintained, as shown by its continued responsiveness to nerve stimulation and alpha- 1 agonists, but the responsiveness of the vessel to a depolarizing dose of $\mathrm{KCl}$ is virtually eliminated.

Concurrent studies in our laboratory have demonstrated that both D-600 and amrinone inhibit calcium uptake by uterine arterial smooth muscle at the same concentrations at which they inhibit mechanical responses of these vessels, and their effects are additive (Fig. 2).

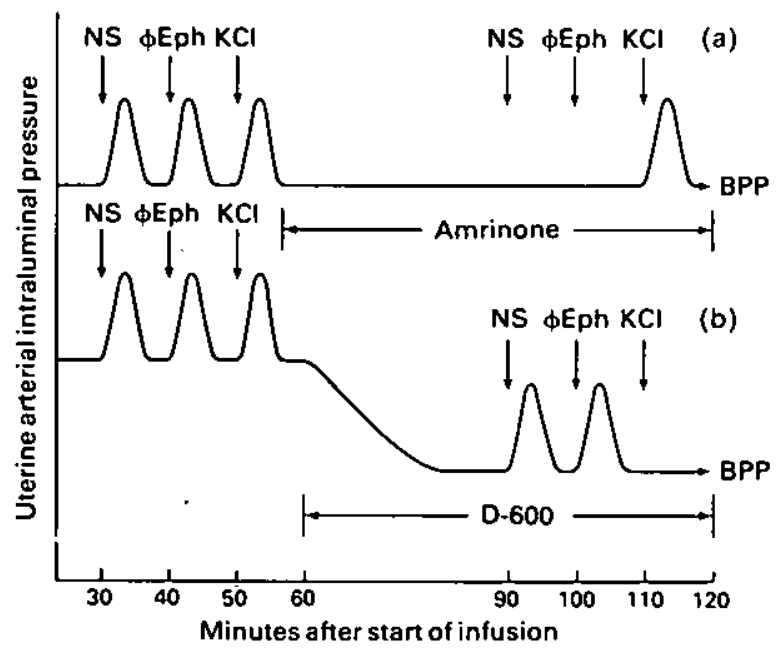

Fig. 1. Schematic diagram of changes in in-vitro responsiveness of uterine arteries from a Day-13 nonpregnant pig to nerve stimulation (NS), phenylephrine (ФEph) and depolarizing dose of $\mathrm{KCl}$, from an established baseline perfusion pressure (BPP), before and after perfusion of amrinone (a) or D-600 (b).

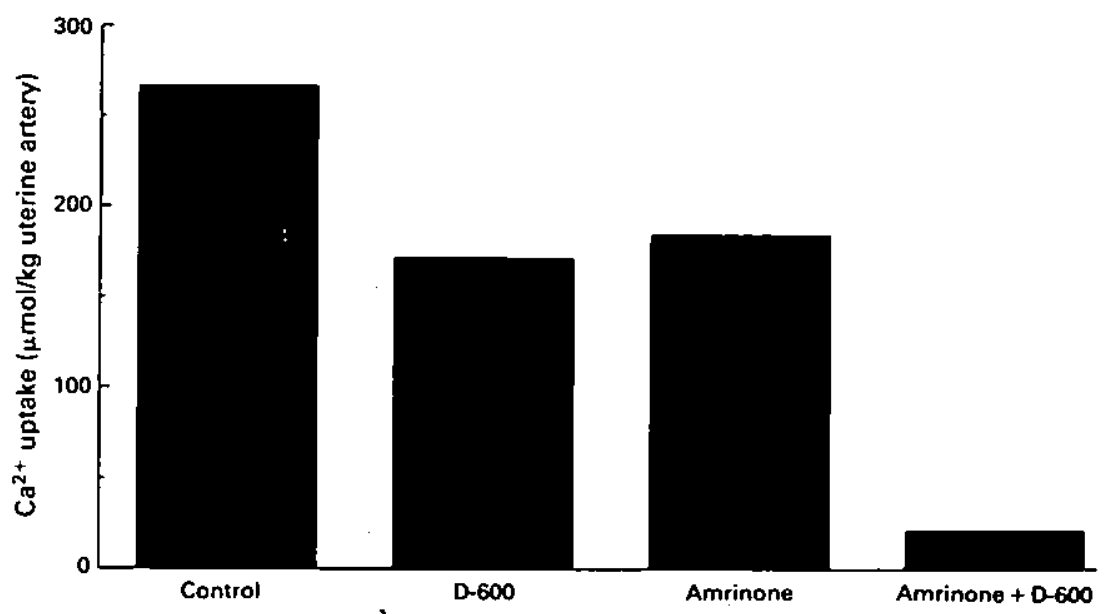

Fig. 2. Uptake of ${ }^{45} \mathrm{Ca}^{2+}$ by uterine arteries from a Day- 13 nompregnant pig co-incubated with phenylephrine and a depolarizing dose of $\mathrm{KCl}$, before and after additions of D.600, amrinone or a combination of D-600 and amrinone. 
Role of catechol oestrogens as uterine vasodilators during the oestrous cycle and pregnancy

Uterine arterial tone is lowest at oestrus when peripheral oestrogen concentrations are high. In pregnancy, tone is further reduced as oestrogen values rise: as a consequence, the vessel is distended and flaccid (Fischer, 1972; Ford, 1982). This appears to be associated only with the increasing oestrogen concentrations, since progesterone is low when the vessel is flaccid at oestrus, but high when it is relaxed in pregnancy. The loss of tone associated with oestrogen exposure is associated with a depressed uptake of calcium by the vessel (Stice et al., 1985). Uterine arteries from pigs at oestrus and on Day 13 of pregnancy have lower $(P<0.05)$ calcium uptake than do vessels taken from animals on Day 13 of the oestrous cycle ( $102 \pm 23$ and $103 \pm 13 v s 183 \pm 15$ (s.e.m.) $\mu \mathrm{M} / \mathrm{kg}$ uterine artery). Furthermore, uterine arteries from pigs during late gestation, which are exposed to still higher levels of circulating oestrogens, show even lower calcium uptake than that observed on Day 13 (49 \pm 9 (s.e.m.) $\mu \mathrm{M} / \mathrm{kg}$ artery by Day 110). In addition, a significant negative correlation $(P<0.001 ; r=-0.93)$ is observed between uterine arterial uptake of calcium and the concentrations of oestrogens in the systemic blood of pigs throughout gestation. No changes are observed in baseline perfusion pressure or the responsiveness of mesenteric arteries to $\mathrm{KCl}$ or phenylephrine throughout the oestrous cycle or pregnancy (S. P. Ford \& S. L. Stice, unpublished observations).

Several lines of evidence suggest that the blockade of 'potential-sensitive' calcium channels associated with uterine hyperaemia is produced by catechol oestrogens which are metabolites of oestrogens found in the circulation when oestrogen concentrations are high (Fishman \& Dixon, 1967; Gelbke, Bottger \& Knuppen, 1975). Synthesis of catechol oestrogens from the parent oestrogens has been shown to occur both in the placenta (Fishman \& Dixon, 1967) and in the uterine arteries themselves in nonpregnant animals (Van Orden, Clancey, Van Orden \& Ford, 1983). The term catechol oestrogen derives from the generic names catechol and oestrogen, one of which is chemical and the other biological in nature. Catechol is the chemical term for an aromatic ring bearing two hydroxyl groups, while oestrogen refers to any structure, natural or synthetic, which possesses the biological properties of the female hormone. Catechol oestrogens are, therefore, oestrogens which contain two instead of one phenolic hydroxyl groups on the ubiquitous aromatic ring and the second hydroxyl is located either on carbon 2 or carbon 4 to produce the 2-hydroxyoestrogens and 4-hydroxyoestrogens, respectively. A cytochrome P450-linked enzyme is thought to be responsible for hydroxylation (Shiverick \& Notelovitz, 1983).

The pig conceptus develops the ability to produce oestrogen on Day 12-13 of gestation (Perry, Heap, Burton \& Gadsby, 1976) as well as the ability to convert these oestrogens to 2- and 4hydroxylated forms (Mondschein, Dey, Davis, Hersey \& Weisz, 1985). We have confirmed the presence of nanogram quantities of 2- and 4-hydroxyoestrogens in uterine flushings from Day-13 pregnant pigs, corresponding to the previously mentioned marked depression of uterine arterial tone that occurs on this day of early pregnancy (J. Williamson, J. P. Rosazza \& S. P. Ford, unpublished results). Local delivery of the catechol oestrogens to the uterine artery may be via uterine lymph. Lymphatics draining a uterine horn in the pig are associated with the unilateral uterine arterial vasculature (Hoggan \& Hoggan, 1882) and act as one route for the drainage of fluid from the uterine horn (Yoffey \& Courtice, 1970). Magness \& Ford (1982) suggested that exposure of uterine arterial smooth muscle to oestrogens may be enhanced by the elevated oestrogen values which occur in the uterine lymph of sows as early as Day 11 of gestation.

When uterine arteries from Day-13 nonpregnant pigs (high tone and contractility) are exposed to catechol oestrogens in vitro, baseline perfusion pressures (tone) declined $(P<0.05)$ over 20 min to $60 \%$ of the initial value. Associated with this was a $75 \%$ reduction in the responsiveness to depolarizing doses of $\mathrm{KCl}$ but no change in the contractile response to phenylephrine. Similar changes are seen after perfusion of a conceptus homogenate of Day-13 pig conceptuses or D-600, suggesting an effect on reducing uptake of calcjum through potential sensitive calcium channels. Free oestrogens (oestrone or oestradiol-17 ) were without effect in altering uterine arterial baseline perfusion pressure or the response to $\mathrm{KCl}$. We have demonstrated a marked effect of catechol 
oestrogen, but not of free oestrogen, in significantly reducing calcium uptake by uterine arteries from Day. 13 nonpregnant pigs to levels found in uterine arteries from pigs in oestrus or on Day 13 of gestation (Stice et al., 1985). These effects of catechol oestrogens are specific for the uterine artery, since the responsiveness of mesenteric arteries (control vessel) to $\mathrm{KCl}$ and phenylephrine as well as their uptake of calcium was unaffected by catechol oestrogens.

\section{Conclusions}

Strong evidence exists for feto-placental control of blood flow during gestation in the pig. Hard \& Anderson (1982) observed a high correlation between uterine blood flow and litter size and weight on Day 90 of gestation in the pig. Furthermore, Wootton, McFadyen \& Cooper (1977) observed a similar relationship between placental blood flow and fetal weight in pigs. Their results also indicate a high correlation between placental blood flow and placental weight. In addition (Hard \& Anderson, 1982), uterine blood flow remains unaltered even in gilts subjected to food restriction from Day 50 to 90 of gestation and experiencing marked declines in body weight, plasma volume and blood volume. Production of catechol oestrogens by each feto-placental unit could function to decrease preferentially the tone of the uterine arteries supplying that unit, thus increasing vessel diameter. Catechol oestrogens are good candidates for local vasodilators since they are rapidly metabolized by catechol-o-methyl transferase in blood (Ball, Knuppen, Haupt \& Breuer, 1972). If administered directly into the uterine artery of the pig, however, catechol oestrogens are equipotent with free oestrogens in their ability to increase uterine blood flow (Van Orden, Ford, Farley \& Rosazza, 1983). The failure of catechol oestrogens to alter the contractile response of the uterine arteria! smooth muscle cells to alpha-1 adrenergic agonist is consistent with the retained ability of the vasculature to respond with transient reductions in flow to stress-induced release of catecholamines from the adrenal medulla.

In summary, these data suggest that the pig conceptus (fetus and/or placenta) locally increases uterine arterial distensibility, through the production of vasodilator (catechol oestrogens?), resulting in increased baseline flow to each fetal-placental unit. The reactivity of the uterine arterial vasculature to adrenergic agonists or other vasoactive agents, however, may or may not be affected. In this way, the conceptus can maintain the locally elevated flows necessary for its surviva! while the maternal system can continue to respond to life-threatening stimuli by transiently rerouting blood flow away from the uterus and towards other vascular beds more necessary for maternal survival (e.g. skeletal muscle). With delivery of each fetus and placenta, the local vasodilatory substance would be removed, allowing the associated uterine arterial vasculature to return rapidly to its normal nonpregnant diameter without marked changes in vessel reactivity.

Journal Paper No. J-11852 of the Iowa Agriculture and Home Economics Experiment Station, Ames; Projects 2443 and 2444. Supported in part by United States Public Health Service Grant HD06380. We thank our colleagues and collaborators for contributions to various aspects of the research mentioned in this manuscript.

\section{References}

Ball, P., Knuppen, R., Haupt, M., \& Breuer, H.J. (1972) Interactions between estrogens and catechol amines 111. Studies on the methylation of catechol estrogens, catechol amines and other catechols by the catechol-o-methyl transferase of human liver. J. clin. Endocr. Metab. 34, 736-746.

Bhalla, R.C., Webb, R.C., Singh, D., Ashley, T. \& Brock, T. (1978) Calcium fluxes, calcium binding, and adenosine cyclic $3^{\prime}, 5^{\prime}$-monophosphate-dependent protein kinase activity in the aorta of spontaneously hypertensive and kyoto wistar normotensive rats. Molec. Pharmacol. 14, 468-477.

Bolton, T.B. (1979) Mechanisms of action of transmitters and other substances on smooth muscle. Physiol. Rev. 59, 606-718.

du Mesnil du Buisson, F. \& Dauzier, L. (1957) Influence de lovariectomie chez la truie pendant la gestation. C. r. Séanc. Soc. Biol. 151, 311-316. 
Fischer, G.M. (1972) In vivo effects of estradiol on collagen and elastin dynamics in rat aorta. Endocrinology 91, 1227-1232.

Fishman, J. \& Dixon, D. (1967) 2-hydroxylation of estradiol by human placental microsomes. Biochemistry, N.Y. 6, 1683-1687.

Ford, S.P. (1982) Control of uterine and ovarian blood flow throughout the estrous cycle and pregnancy in the ewe, sow and cow. J. Anim. Sci. 55 (Suppl. 2), 32-42.

Ford, S.P. \& Christenson, R.K. (1979) Blood flow to uteri of sows during the estrous cycle and early pregnancy: local effect of the conceptus on the uterine blood supply. Biol. Reprod. 21, 617-624.

Ford, S.P., Weber, L.J. \& Stormshak, F. (1976) In vitro response of ovine and bovine uterine arteries to prostaglandin $F_{2 \alpha}$ and periarterial sympathetic nerve stimulation. Biol. Reprod. 15, 58-65.

Ford, S.P., Weber, L.J. \& Stormshak, F. (1977) Role of estradiol- $I 7 \beta$ and progesterone in regulating constriction of ovine uterine arteries. Biol. Reprod. 17, $480-483$.

Ford, S.P., Reynolds, L.P., Farley, D.B., Bhatnagar, R.K. \& Van Orden, D.E. (1983) Role of estrogen and progesterone in altering autonomic function of uterine arteries during the estrous cycle and early pregnancy in gilts. J. Anim. Sci. 57 (Suppl. I), 337, Abstr.

Ford, S.P., Reynolds, L.P., Farley, D.B. Bhatnagar, R.K. \& Van Orden, D.E. (1984a) Interaction of ovarian steroids and periarterial $\alpha_{1}$-adrenergic receptors in altering uterine blood flow during the estrous cycle of gilts. Am. J. Obstet. Gynecol. 150,480-484.

Ford, S.P., Reynolds, L.P. \& Ferrell, C.L. (1984b) Blood flow, steroid secretion and nutrient uptake of the gravid uterus during the periparturient period in sows. J. Anim. Sci. 59. 1085-1091.

Ganong, W.F. (1977) Review of Medical Physiology, 8th edn, p. 7I. Lang Medical Publ., Los Altos, CA.

Gelbke, H.P., Bottger, M. \& Knuppen, R. (1975) Excretion of 2-hydroxyestrone in urine throughout human pregnancies. J. clin. Endocr. Metab. 41, 744-750.

Giles, R.E. \& Miller, J.W. (1967) The catechol-o-methyl transferase activity and endogenous catecholamine content of various tissues in the rat and the effect of administration of U-052I (3',4'-dihydro-2-methyl propiophenone). J. Pharmacol. exp. Ther. 158, 189-194.

Greiss, F.C., Jr \& Gobble, F. (1967) Effect of sympathetic nerve stimulation on the uterine vascular bed. $A m . J$. Obstet. Gynec. 97, 962-967.

Hard, D.L. \& Anderson, L.L. (1982) Interaction of maternal blood volume and uterine blood flow with porcine fetal development. Biol. Reprod. 27, 79-90.

Hoggan, G. \& Hoggan, F.E. (1882) On the comparative anatomy of the lymphatics of the uterus. J. Anat. Physiol. (London) 16, 51-89.

Janis, R.A. \& Scriabine, A. (1983) Sites of action of $\mathrm{CA}^{2+}$ channel inhibitors. Biochem. Pharmacol. 32, 3499-3507.

Knight, J.W., Bazer, F.W., Thatcher, W.W., Franke, D.E. \& Wallace, H.D. (1977) Conceptus development in intact and unilaterally hysterectomizedovariectomized gilts: interrelations among hormonal status, placental development, fetal fluids and fetal growth. J. Anim. Sci. 44, 620-637.
Lloyd, T. \& Weisz, J. (1978) Direct inhibition of tyrosine hydroxylase activity by catechol estrogens. J. biol. Chem. 253, 4841-4843.

Magness, R.R. \& Ford, S.P. (1982) Steroid concentrations in uterine lymph and uterine arterial plasma of gilts during the estrous cycle and early pregnancy. Biol. Reprod. 27, 871-877.

McKercher, T.C., Van Orden, L.S., Ill, Bhatnagar, R.K. \& Burke, J.P. (1973) Estrogen-induced biogenic amine reduction in rat uterus. $J$. Pharmacol. exp. Ther. 185, 514-522.

Meisheri, K.D., Hwang, O. \& Van Breemen, C. (1981) Evidence for two separate $\mathrm{Ca}^{2+}$ pathways in smooth muscle plasmalemma. J. membr. Biol. 59, 19-25.

Mondschein, J., Dey, S.K., Davis, D.L., Hersey, R.M. \& Weisz, J. (1985) Porcine blastocysts [BCs] synthesize catechol estrogens [CE]. Am. J. Obstet. Gynecol. 151 (Suppl.), 92, Abstr.

Morris, B. \& Sass, M.B. (1966) The formation of lymph in the ovary. Proc. R. Soc. Lond. B 164, 577-591.

Pedroza-Garcia, E., Garcia-Bienere, W., Inglesi, J., Szerezewski, A. \& Rosner, J.M. (1975) Interactions in the uptake between catecholamines and estradiol in the human uterus. Am. J. Obstet. Gynec. 122, 96-100.

Perry, J.S., Heap, R.B., Burton, R.D. \& Gadsby, J.E. (1976) Endocrinology of the blastocyst and its role in the establishment of pregnancy. J. Reprod. Fert., Suppl. 25, 85-104.

Pope, W.F., Maurer, R.R. \& Stormshak, F. (1982) Distribution of progesterone in the uterus, broad ligament and uterine arteries of beef cows. Anat. Rec. 203, 245-250.

Shiverick, K.T. \& Notelovitz, M. (1983) Regulation of cylochrome P-450-dependent catechol formation in ral liver microsomes: evidence for involvement of estrogen recéptors. Biochem. Pharmacol. 32, 2399-2403.

Stice, S.L., Van Orden, D.E. \& Ford, S.P. (1985) Role of estrogen (E) and catechol estrogen (CE) in reducing uterine arterial tone and ${ }^{45} \mathrm{Ca}$ uptake. $\mathrm{Am}$. J. Obstet. Gynecol. 151 (Suppl.), 112, Absir.

Van Orden, D.E., Goodale, D.B., Baker, H.A., Farley, D.B. \& Bhatnagar, R.K. (1980) Uterine catecholamines and prostaglandins during the estrous cycle of the rat. Endocrinology 106, 1650-1654.

Van Orden, D.E., Farley, D.B., Reynolds, L.P. \& Ford, S.P. (1982) Estrogen-induced uterine hyperemia: decay of the response. Am. J. Obstet. Gynecol. 142 (Suppl.), 10, Abstr.

Van Orden, D.E., Clancey, C.J., Van Orden, C.L. \& Ford, S. P. (1983) Synthesis of catechol estrone by porcine uterine arteries. Endocrinology 112 (Suppl.), 302, Abstr.

Van Orden, D.E., Ford, S.P., Farley, D.B. \& Rosazza, J.P. (1983) Induction of uterine arterial vasodilation by estradiol and catechol estradiols. Am. J. Obstet. Gynecol. 145 (Suppl.), 58, Abstr.

Wootton, R., McFadyen, I.R. \& Cooper, J.E. (1977) Measurement of placental blood flow in the pig and its relation to placental and fetal weight. Biol. Neonate 31, 333-339.

Yoffey, J.M. \& Courtice, F.C. (1970) Lymphatics, Lymph and Lymphomyeloid Complex. Academic Press, London. 